\title{
Problematic Internet Use, Social Needs, and Social Support Among Youth
}

\section{Dora K. Prievara, Bettina F. Piko \& Aleksandra Luszczynska}

International Journal of Mental Health and Addiction

ISSN 1557-1874

Int J Ment Health Addiction DOI 10.1007/s11469-018-9973-x
Affiliated with the Auckland University of Techt Medicine \& Psychiatry at West Virginia Univer Internationa ONLINE FIRST of Mental Health and Addiction

Volume 11 • Number 4 • August 2013 
Your article is protected by copyright and all rights are held exclusively by Springer Science+Business Media, LLC, part of Springer Nature. This e-offprint is for personal use only and shall not be self-archived in electronic repositories. If you wish to selfarchive your article, please use the accepted manuscript version for posting on your own website. You may further deposit the accepted manuscript version in any repository, provided it is only made publicly available 12 months after official publication or later and provided acknowledgement is given to the original source of publication and a link is inserted to the published article on Springer's website. The link must be accompanied by the following text: "The final publication is available at link.springer.com". 


\title{
Problematic Internet Use, Social Needs, and Social Support Among Youth
}

\author{
Dora K. Prievara $^{1}$ - Bettina F. Piko ${ }^{2}$ (D) - Aleksandra Luszczynska ${ }^{3,4}$ \\ Published online: 19 September 2018 \\ (C) Springer Science+Business Media, LLC, part of Springer Nature 2018
}

\begin{abstract}
The Internet is essential for the teenagers and young adults who are spending hours online every day. In an effort to better understand the role of the Internet in their lives, we hypothesized that users increased their online time for social reasons. In this online survey, 408 (204 girls and 204 boys; aged between 14 and 24 years) participants were recruited from high schools and universities. The questionnaire included scales about the problematic Internet use (PIU), need to belong, shyness, loneliness, and perceived social support. PIU was directly related to a higher need to belong, higher shyness, and higher loneliness. The perceived support was associated indirectly with PIU. Loneliness showed the most decisive role in the development of PIU, and social support also contributed through this variable. Our data indicate that social support from the offline environment can be a protective factor against PIU, emphasizing the important roles of friends and family.
\end{abstract}

Keywords Problematic Internet use $\cdot$ Loneliness $\cdot$ Shyness $\cdot$ Need to belong $\cdot$ Social support . Youth

In recent years, the Internet has become the most important source of information, entertainment, and communication for youth. Young people spend an inordinate amount of time online. For example, $82 \%$ of university students and $60 \%$ of teenagers access the Internet daily (McIntyre et al. 2015). The percentage is similar among Hungarian teenagers (Ságvári 2012). Adolescents spend online $2.5 \mathrm{~h}$ day on weekdays, and $3.5 \mathrm{~h}$ day on the weekend (Žumárová 2015), particularly on social platforms (Naeemi et al. 2014). These websites are the

Bettina F. Piko

fuzne.piko.bettina@med.u-szeged.hu

1 Institute of Applied Health Science and Health Development, University of Szeged, Szeged, Hungary

2 Department of Behavioral Sciences, University of Szeged, Szentharomsag str. 5., Szeged 6722, Hungary

3 University of Colorado, Colorado Springs, USA

4 SWPS University of Social Sciences and Humanities, Warsaw, Poland 
most popular in Hungary as well (Kitta 2012). One of the aims of the current study was to detect the Internet using habits of Hungarian youth, while comparing them to other samples of international users. By making these comparisons, we expect to identify key elements that could comprise an effective prevention program.

The Internet offers quick answers, immediate rewards, and feedbacks, with a great deal of benefits for its users (Ko et al. 2009). On the other hand, some websites and activities are risky in the way that they provide a possibility to get lost in the virtual world, while healthy Internet use can be characterized by a determined goal while using the Internet and a rational time frame (Davis 2001). In addition, having online friendships does not necessarily support the development of social skills or provide real solution for loneliness (Leung 2004).

Some researchers have argued that there is a relationship between social networking sites (such as Facebook or Twitter) and depression (Jelenchick et al. 2013). Visitors find social and emotional support in the virtual world, a sense of belonging, being a part of a community while they are communicating online with other people. Thus, users can compensate the inadequate social support and attention from their real life with online community access (Vandelanotte et al. 2009). Excessive Internet use can even serve as a way to escape from reality (Leung 2011) but it also may lead to dependency and difficulty interacting with the offline world (Leung 2004).

Young described the dependency to the online world as a new clinical disorder, namely Internet addiction (Young 1998). In her theory, Internet addiction was defined as excessive time spent on online activities to the extent of it adversely affecting user's physical and mental health, such as negatively influencing academic or work performance, and social/marital relationships. The users feel an uncontrollable urge to go online and they may be aggressive and nervous when they do not have access to the Internet (Young 2004). There is still some debate about the terminology of excessive Internet use and related symptomatology. Whereas many researchers use the term "Internet addiction" as a form of behavioral addiction (Aboujaoude 2010) the DSM-V did not capture this concept (APA 2013). Shapira et al. (2003) argued that the criteria of addiction were not entirely met, and they provided a less controversial terminology of problematic Internet use (PIU). PIU covers a maladaptive preoccupation with Internet use, experienced as irresistible use for periods of time longer than intended and significant distress or impairment resulting from the behavior. PIU emphasized the negative effects of the excessive Internet use (e.g., social relationships, physical health, work, or school performance) without a pathological diagnosis and labelling of dependency or addiction (Spada 2014).

We apply the term PIU in our study, assuming that the greater the amount of time spent on the Internet, the more serious the negative consequences are on the user's private life even if not at pathological levels. Three domains of PIU account for these negative consequences (Demetrovics et al. 2008), i.e., Obsession (e.g., one is daydreaming about the Internet when being offline and thinking about what to do next time online); Neglect (e.g., one usually forgets to do average activities like eating/sleeping and other commitments); and Control disorder (e.g., one has problems with time management and leaving the online world).

An extant literature has reported associations between PIU and social variables, such as loneliness, shyness, and social anxiety. For example, Fallahi compared university students' groups, namely normal users, at risk users, and addicted users, and found that the addicted group reported more loneliness than the others (Fallahi 2011). Similarly, a correlation was found between higher scores of Internet addiction and loneliness (Esen et al. 2013), whereas there were no significant results on the role of social self-efficacy. Shyness was also positively 
associated with PIU indicating a desire to find social relationships on the Internet (Eroglu et al. 2013).

Among the social variables, social support received from significant others may be an important issue for youth. Parental care and emotional support seemed to provide protection against PIU: low satisfaction with the family predicted addictive symptoms to Internet usage (Yen et al. 2009). Youth who perceived low friendship quality often used the Internet for communication and in turn a reduction in depression and social anxiety (Selfhout et al. 2009). On the other hand, supportive parental background showed negative correlations with PIU among teenagers ( $\mathrm{Li}$ et al. 2014), especially when reporting a strong, positive relationship with their mother (Gunuc and Dogan 2013).

Based on this empirical work, social support and needs seem to be important correlates of youth's Internet use. The question is how important are these social factors in determining problematic Internet use. Thus, the main goals of our research are the following: (1) to map Internet using habits in a sample of youth and (2) to investigate associations between problematic Internet use (PIU) and certain social variables (namely perceived social support from the significant others, loneliness, shyness, and need to belong).

While social support and social needs have already been studied, the role of need to belong as an indicator of social need has not yet been empirically established. Therefore, our aim with this research was to map possible social variables of Internet usage, especially those with controversial research data, such as social needs and support. We hypothesized that PIU might be associated with lower levels of social support and higher levels of loneliness, shyness, and the need to belong. Furthermore, we investigated whether these variables may operate directly or indirectly.

\section{Methods}

\section{Participants}

The sample consisted of 408 respondents (50\% males and 50\% females) from high schools $(N=163)$ and universities $(N=245)$. The average age was 20.81 years $(\mathrm{SD}=$ 2.63 years, ages between 14 and 24 years). Participants answered an online, anonymous survey that took approximately $20-25 \mathrm{~min}$ to complete. The survey was available between January 2014 and July 2014 at different online social networking sites and online forums (university groups on Facebook and Hungarian writing sites) which were popular online platforms among youth.

\section{Measures}

All the scales and questionnaire items were translated into Hungarian and back translated by bilingual translators, and most of them previously were applied to Hungarian youth populations. Reliability coefficients for all scales and subscales used in the study are presented in Table 2; Cronbach's alphas (all $\alpha \mathrm{s}>$.66) were adequate for all subscales applied to measure the investigated constructs $(\alpha<.60$ may be considered unacceptable, and alphas $>.70$ are acceptable, cf. Murphy and Davidshofer 1988). Table 2 also displays the fit indices for modeldata fit obtained for confirmatory factor analyses, assuming a three-factor structures of problematic Internet use and social support and one-factor structure for shyness, need for 
belonging, and loneliness. All confirmatory factor analyses yielded acceptable fit between collected data and assumed factorial model.

The Problematic Internet Use Questionnaire (Demetrovics et al. 2008) is an 18-item selfreport scale that measures the extent of how risky Internet usage can be. Items are scored from $1=$ never to $5=$ always. This test has three factors, i.e., Obsession, Neglect, and Control disorder. Demetrovics et al. (2008) established a three-factor structure for Hungarian youth: (1) mental engagement with the Internet through fantasizing about the use and the person cannot wait for the next time to get online; (2) neglect of the everyday activities and the essential needs such that housework, job, studies, eating, social relationships, and other activities decrease as a result of heavy Internet usage; (3) difficulties in controlling Internet usage such that people have problems with controlling their usage of the Internet more often and for a longer time than they have planned. Earlier studies (Demetrovics et al. 2008) showed that PIU subscales have good psychometric properties in Hungarian population, with high reliability ( $\alpha$ s of .74-.87), high 3-week stability ( $r s$ from .76 to .90), and acceptable discriminant validity (e.g., confirmed by negligible associations with alcohol or illicit drug use and significant but weak associations with the use of gaming machines).

The Need to Belong Scale (Leary et al. 2013) is a 10-item self-report scale with good reliability and validity (Leary et al. 2013) that measure the need to attach. Each item is scored on a scale from 1 (strongly disagree) to 5 (strongly agree).

The Revised Cheek and Buss Shyness Scale (Rai 2011) consists of 13 items. Good validity and reliability of the scale was shown in the study by Rai (2011). The items are scored from 1 (very uncharacteristic or untrue, strongly disagree) to 5 (very characteristic or true, strongly agree).

For measuring loneliness, we used the Hungarian adaptation (Csóka et al. 2007) of the UCLA Loneliness Scale (Russel et al. 1980). The Hungarian version has good psychometric properties (Csóka et al. 2007). This scale has 20 items, which are scored from 1 (strongly disagree) to 4 (strongly agree).

The Measures of Perceived Social Support (Turner and Marino 1994), the Hungarian version (Piko 2000), was used to assess the level of satisfaction with the support experienced from mother, father, and best friend. Each of the three scales contained six items and was scored such that high scores indicate high satisfaction with the perceived support. Satisfaction was measured by the amount of agreement with the items. Responses varied from "not all like my experience" (0) to "much like my experience" (3). The final scales were coded from 0 to 18 .

\section{Data Analysis}

First, descriptives and correlations were examined among the study variables. The aim of the correlation analysis was to test bidirectional associations between each of the variables of the study. In addition, before the path analysis, we intended to test bidirectional connections which helped us develop the final path model. We thought these associations might help better understand the whole picture, e.g., connections between gender and all of the items of problematic Internet use. We used path analysis with the maximum likelihood estimation (IBM SPSS Amos; version 22) to test the relationships among the study variables. The path model tested in our study (henceforth, the hypothesized model) included all predictor, dependent, and control variables, as well as the hypothesized associations between these variables. The model is presented in Fig. 1. In particular, the hypothesized model assumed that problematic Internet use was directly related to a need to belong, shyness, and loneliness. 


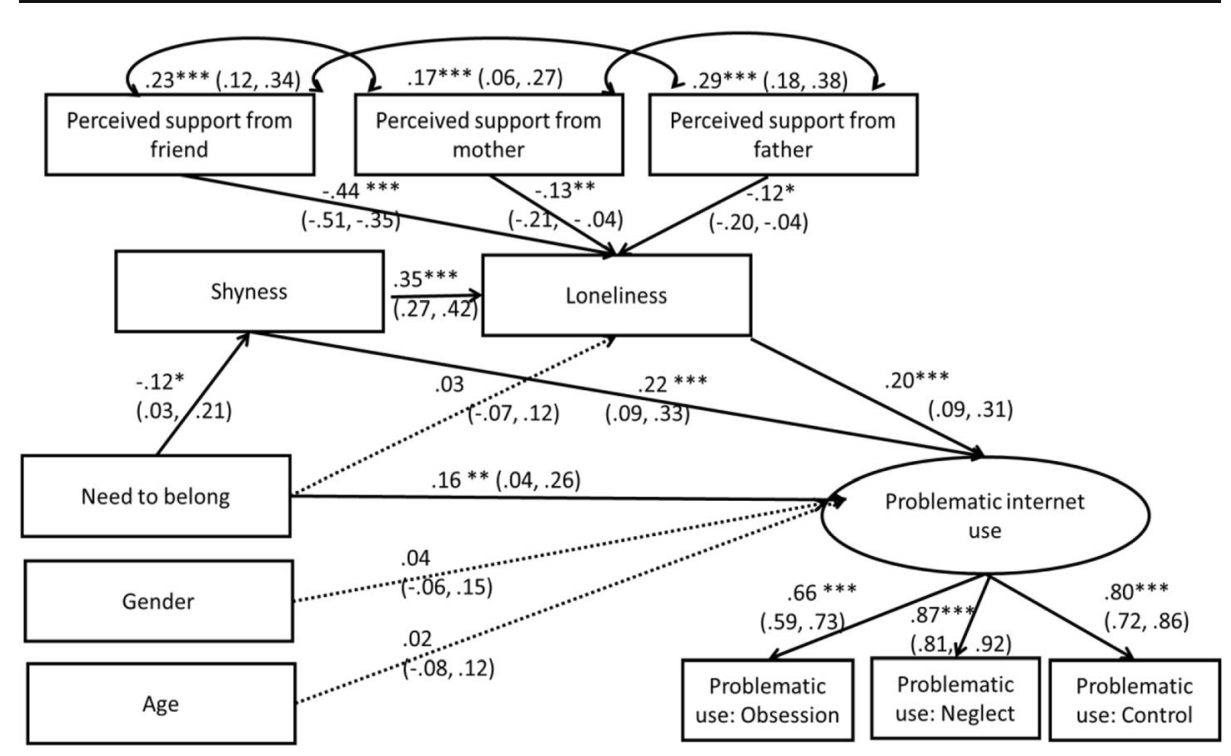

Fig. 1 Results of path analysis: predictors of problematic Internet use. Standardized regression coefficients and bootstrap-corrected confidence intervals for standardized path coefficients (in parentheses) are reported

Problematic use of Internet was also indirectly related to need to belong, shyness, and perceived social support from three sources.

The significance of indirect effects $(\theta)$ was evaluated with bootstrapping method $(10,000$ bootstraps) to calculate $95 \%$ corrected and accelerated confidence intervals $\left(\mathrm{BC}_{\mathrm{a}} \mathrm{CI}\right)$. This approach to test our main hypotheses on direct and indirect coefficients is in line with Wasserstein and Lazar's (2016) suggestion to supplement or replace $p$ values with estimation of confidence intervals of respective coefficients.

The fit between the hypothesized model and collected data was evaluated using fit indices usually applied in structural equation modeling to estimate model-data fit, with CFI and TLI values $>.90$ considered marginally adequate and values $>.95$ indicating good model-data fit (Byrne 2010). In turn, RMSEA values $<.10$ are considered marginally adequate whereas those $<.08$ represent good model-data fit (Byrne 2010). Acceptable/good values of fit indices suggest that the collected data match well the hypothesized model (assuming all hypothesized associations). Mardia's coefficient indicated a small-to-moderate deviation from multivariate normality of variables in the model (critical ratio of 7.91). There were no missing values.

GPower calculator was used to evaluate the sample size. Assuming that some effects of the predictor variables may be small $\left(f^{2}=.05\right)$ of variables in the model, it was estimated that 400 participants were needed to obtain significant effects $(p=.05$, power $=.85)$.

\section{Results}

\section{Descriptive Statistics}

The time participants spent online is shown in Table 1 . Nearly $9 \%$ of participants used the Internet for $1 \mathrm{~h}$ or less per day; $11 \%$ used it daily for $1-2 \mathrm{~h}, 35.5 \%$ for $2-4 \mathrm{~h}$, and $44.6 \%$ for 
Table 1 The amount of daily Internet use in percent

Chi-square test: $p>.05$ for gender difference

\begin{tabular}{lrrr}
\hline & Total & Males & Females \\
\hline Not using the Internet everyday & 0.5 & 1.0 & 0.0 \\
Few minutes & 1.2 & 2.5 & 0.0 \\
30 min & 2.5 & 2.9 & 2.0 \\
$1 \mathrm{~h}$ & 4.4 & 5.4 & 3.4 \\
$1-2 \mathrm{~h}$ & 11.3 & 12.3 & 10.3 \\
$2-4 \mathrm{~h}$ & 35.5 & 32.4 & 38.7 \\
More than $4 \mathrm{~h}$ & 44.6 & 43.6 & 45.6 \\
\hline
\end{tabular}

more than $4 \mathrm{~h}$. This usage suggests that $80 \%$ of respondents used the Internet more than $2 \mathrm{~h}$ day. There were no gender differences in time spent online $(p>.05)$.

Descriptive statistics for the scales are shown in Table 2. In the absence of a standard cutoff point, PIU was defined by a score more than two standard deviations above the mean as the study suggested in which the original scale was introduced (Demetrovics et al. 2008). This is because the results could not be compared either with clinical research results or with other previously validated questionnaires yet. In this case, the cutoff point was 51.4, and thus, $4.9 \%$ (6.4\% of males and 3.4\% females; $p>.05$ ) of the sample belonged to the group of problematic Internet users. The respondents had the highest level of perceived social support from their best friend, followed by perceived social support from their mother, whereas the level of perceived social support from father was the lowest.

\section{Correlation Matrix}

Table 3 shows bivariate relationships between the study variables. The results showed significant positive correlations between total PIU and the social scales: with the level of

Table 2 Descriptive statistics for study variables

\begin{tabular}{|c|c|c|c|c|c|c|}
\hline & \multirow[t]{2}{*}{$\begin{array}{l}\text { Min.-- } \\
\max .\end{array}$} & \multirow[t]{2}{*}{ Mean } & \multirow[t]{2}{*}{ SD } & \multirow[t]{2}{*}{$\begin{array}{l}\text { Cronbach's } \\
\text { alpha }\end{array}$} & \multicolumn{2}{|c|}{$\begin{array}{l}\text { Results of model-data fit for } \\
\text { confirmatory factor analysis }\end{array}$} \\
\hline & & & & & $\begin{array}{l}\text { Values of fit } \\
\text { indices: NFI and } \\
\text { CFI }^{b}\end{array}$ & $\begin{array}{l}\text { Values of } \\
\text { RMSEA }^{\mathrm{b}}\end{array}$ \\
\hline Problematic Internet use $\mathrm{e}^{\mathrm{a}}$ & $18-65$ & 33.02 & 9.18 & .87 & All > 90 & .062 \\
\hline Obsession & $6-22$ & 9.2 & 3.1 & .77 & & \\
\hline Neglect & $6-22$ & 11.8 & 3.6 & .66 & & \\
\hline Control disorder & $6-25$ & 12.0 & 4.0 & .80 & & \\
\hline \multicolumn{7}{|l|}{ Social needs } \\
\hline Loneliness & $21-74$ & 38.4 & 10.3 & .89 & All $>.90$ & .090 \\
\hline Shyness & $13-60$ & 36.2 & 9.6 & .86 & All > 90 & .089 \\
\hline Need to belong & $9-65$ & 37.31 & 10.42 & .77 & All $>.90$ & .070 \\
\hline Social support & & & & & All > .90 & .067 \\
\hline Perceived support from father & $6-24$ & 15.93 & 5.64 & .94 & & \\
\hline Perceived support from mother & $6-24$ & 19.73 & 4.27 & .92 & & \\
\hline $\begin{array}{l}\text { Perceived support from best } \\
\text { friend }\end{array}$ & $6-24$ & 20.37 & 3.86 & .89 & & \\
\hline
\end{tabular}

a The cutoff point was 51.4 , and $4.9 \%$ of the sample belonged to problematic users; ${ }^{\mathrm{b}}$ confirmatory factor analysis was applied to test the factorial structure and the data fit to: the models assuming three-factors (associated) for problematic Internet use and for social support, and models assuming one factor for loneliness, shyness, and need to belong. All models indicated that the collected data represented marginal or acceptable fit for the assumed factorial structure 


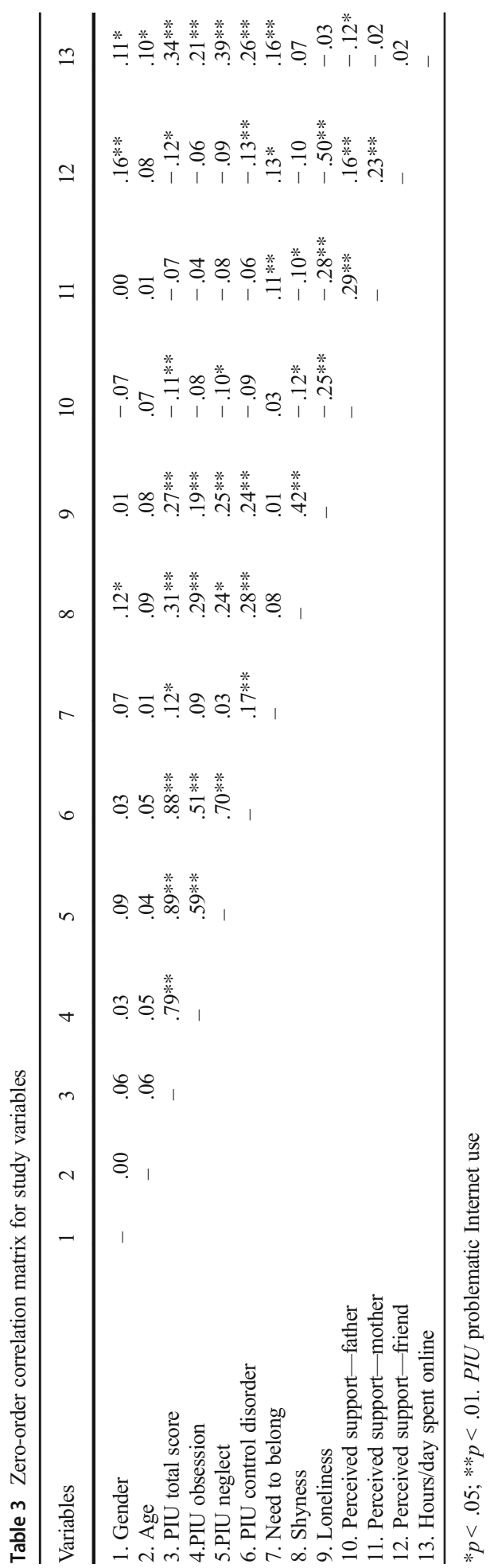


shyness $(r=.31 p<.01)$, loneliness $(r=.27 p<.01)$, and need to belong $(r=.12 p$ $<.05)$. Negative correlations were found between total PIU and the level of perceived support from the father $(r=-.11 p<.01)$ and best friend $(r=-.12 p<.05)$. The time spent online was positively correlated with PIU (particularly with Neglect), gender, age, need to belong, and negatively with father support. The three subscales of PIU were also positively correlated with the social variables and negatively associated with perceived support. The Neglect subscale had a negative correlation with perceived support from the father $(r=-.10 p<.05)$, and the Control disorder subscale had a negative correlation with perceived support from best friend $(r=-.13 p<.01)$. There were no correlations with age and gender except for the amount of perceived support from friend and shyness.

\section{Results of Path Analysis}

Path analysis indicated acceptable fit between the hypothesized model, assuming all hypothesized associations, and collected data, with $\chi^{2} / \mathrm{df}=1.84$, AGFI $=.951, \mathrm{CFI}=.965$, TLI $=$ $.950, \mathrm{RMSEA}=.045$, and SRMR $=.058$. Overall, the variables in the model explained $15 \%$ of the variance in the latent variable, problematic use of Internet, $39 \%$ of the variance in loneliness and $2 \%$ of the variance in shyness.

Figure 1 presents the standardized solution. The direct associations assumed in the hypothesized model (e.g., between the three predictors, need to belong, shyness, loneliness, and problematic Internet use) were significant (Fig. 1), except for the relationship between need to belong and loneliness. The relationships between the two control variables, age and gender, and problematic use of Internet were not significant (Fig. 1).

Three direct effects were found: high levels of the problematic use of Internet were directly associated with a higher need to belong, higher shyness, and higher loneliness (for values of standardized coefficients, see Fig. 1). Furthermore, four variables had significant indirect effects on problematic Internet use: need to belong $\left(\theta=.025,95 \% \mathrm{BC}_{\mathrm{a}} \mathrm{CI} .005, .053\right.$; $p=.013)$, shyness $\left(\theta=.024,95 \% \mathrm{BC}_{\mathrm{a}} \mathrm{CI} .010, .041 ; p=.001\right)$, social support from friend $(\theta=-.070,95 \% \mathrm{CCI}-.029,-.118 ; p=.001)$, social support from mother $(\theta=-.018,95 \%$ $\left.\mathrm{BC}_{\mathrm{a}} \mathrm{CI}-.005,-.041, p=.007\right)$, and social support from father $\left(\theta=-.013,95 \% \mathrm{BC}_{\mathrm{a}} \mathrm{CI}\right.$ $-.003,-.029 ; p=.003)$.

Additional analyses compared the hypothesized model with a nested model in which the three paths were found to be not significant (from gender and age to problematic Internet use, from need to belong to loneliness) were constrained to zero. The comparisons between the hypothesized and nested models indicated that the two models had similar fit, with $\Delta \chi^{2}=$ $1.106, p=.776, \Delta \mathrm{TLI}=-.008$. Thus, the model assuming these paths are negligible was accepted.

\section{Discussion}

Despite the fact that Internet use is an indisposed part of our life and it has many benefits, there are a number of risks and negative consequences to this usage. These negative consequences are particularly true in the case of the online social world; while it provides opportunity for developing social contacts with others (Naeemi et al. 2014; Ko et al. 2009), it may also lead to a number of harmful psychological health problems 
(Jelenchick et al. 2013). Thus, the social aspects of the online world are rather controversial, whether Internet use may be beneficial or harmful to our offline social life. The concept of problematic Internet use (PIU) provides a good rationale for investigating such a relationship with social needs and social support.

Our sample's Internet using habits were similar to a recent study from the Czech Republic (Žumárová 2015). In an earlier Hungarian study, the participants were asked about their weekly Internet usage not about the daily use in 2004 (Demetrovics et al. 2008; Demetrovics et al. 2004). This finding shows $27 \%$ of participants were using it less than $1 \mathrm{~h}$ and $20 \%$ more than $5 \mathrm{~h}$ a day (Demetrovics et al. 2004). Compared to the current results, more than $45 \%$ of the participants reported being online for more than $4 \mathrm{~h}$ day. We must take into account that these habits have changed over time due to a continual increase in Internet usage. The daily online time seems to have increased annually: according to a European comprehensive report, 9-16-year-old Hungarian children spent 85 min day online in 2012 which was close to the European average (Ságvári 2012).

The second goal of the study was to assess PIU in the sample. Based on the cutoff point, $4.9 \%$ of the sample belonged to problematic Internet users, slightly higher than the frequency (4.3\%) in the abovementioned Hungarian study (Demetrovics et al. 2008; Demetrovics et al. 2004). In a recent European survey, using a slightly different measure, $4.4 \%$ of youth were characterized by PIU (Durkee et al. 2012). Similar to previous studies, gender did not play a role in the PIU scores and the mean scores were similar to those of other samples, except for Control disorder since this level was higher in our sample (Ságvári 2012).

In terms of the bivariate relationship between PIU and the social scales, the total PIU and its subscales showed significant associations with need to belong, shyness, and loneliness. These results support findings from former studies (Esen et al. 2013; Eroglu et al. 2013). In addition, there was a slight positive correlation between need to belong and shyness, and a stronger correlation between shyness and loneliness. For many people, the online world may serve as a modern way of escapism from the problems of the real world (Leung 2011). Our result may be in concordance with previous research results concerning Internet usage as a compensation for offline social activities, especially for girls (Vandelanotte et al. 2009). The role of gender was also detected in bivariate relationships, namely being female was positively correlated with shyness, time spent online, and perceived support from the best friend. This suggests that not only the personal friendship offers girls a safe world to communicate but also the online world (particularly for shy girls), e.g., with more time to think over and revise thoughts and reactions, often with the same friend. Further research is needed to test this hypothesis about the role of online/offline world in friendships. Investigating the role of social support, the summary score of PIU was significantly and negatively related to perceived support from father and friend. In the case of the subscales, Neglect showed a negative correlation with father support, while Control disorder was negatively correlated with friend support. In addition, perceived social support from the best friend provided the most important protection against loneliness; these findings are in concordance with previous research (Yen et al. 2009).

Finally, we used path analysis to gain a deeper understanding into the role of these social needs and support variables. According to the findings, PIU was directly related with higher need to belong, higher shyness, and higher loneliness. The perceived support was associated indirectly with PIU through loneliness, especially social support from a 
best friend due to the age-related social needs of the respondents. Thus, while all of the social needs variables play roles in PIU, loneliness seems to show the most decisive role; moreover, social support also may be a contributor through this variable.

There are some limitations to the study that should be noted here. Some scales had relatively lower reliability; these need to be tested in further studies. We do not yet have diagnostic criteria of PIU based on cutting scores. Due to the convenience sample which was not randomly selected from the targeted population, results are not generalizable. All in all, we really think that-despite these limitations - our findings may significantly contribute to the literature on PIU, particularly on the role of social needs and variables in young populations.

Overall, the results of this study suggest that loneliness plays a central role in youth's problematic Internet use that may also stem from the lack of social support from peers as well as from parents. Loneliness is also associated with shyness representing the lack of necessary social skills that would be a prerequisite for a good working social relationship. This is particularly risky in terms of addiction when a person's need to belong is high. Moreover, lonely youth who seek social support online can also easily become victims of cyberbullying (Kowalski et al. 2014). The Internet can change people's social lives, particularly since it alters interpersonal communication. The debate whether it is improving or harming is still in progress. The paradox lies in the controversial role of online communication: while it may elevate frequency of communication, it declines social involvement, that is, people often substitute strong ties with weak ties (Kraut et al. 1998). Our findings are in concordance with this idea since these youth spend a lot of times online, yet they tend to be shy and lonely that may contribute to problematic Internet use instead of social support in real life, particularly those having high social needs. As it seems, the online social activities cannot satisfy their needs. This association also suggests that having satisfying social relationships and offline social network and support from friends and parents can protect youth from loneliness and PIU through practicing communication skills face-to-face. As a previous study revealed, frequent Internet users are not only more likely to be lonely but also to some extent to lack the emotional and social skills (Engelberg and Sjöberg 2004). All these suggest that those having the appropriate social skills may be protected from being lonely and shy, and even if they have a high social need, they do not necessarily turn to Internet use instead of real social relationships.

In conclusion, for practical implications, these data suggest that social and communication skills training should be an integral part of the efficient prevention programs. A prevention program on Internet use should also include both peers and parents. Involving parents is especially important since many parents are not well-informed about the risks of excessive Internet use. Such a program can also serve as a possibility to build healthy relationship with the parents. Although peers are better informed about the online activities, we should persuade them to see the advantages of offline social activities. While excessive Internet use and problems around it is getting more and more into the focus of science, youth and their parents should be more informed about the risks and many social and health consequences and possible prevention particularly for those who are at special high risk, e.g., lonely youth.

Acknowledgements The authors would like to offer their thanks to Kevin M. Fitzpatrick for his helpful comments on the paper. 
Compliance with Ethical Standards All procedures followed were in accordance with the ethical standards of the responsible committee on human experimentation (institutional and national) and with the Helsinki Declaration of 1975, as revised in 2000. Informed consent was obtained from all participants included in the study.

Conflict of Interest The authors declare that they have no conflict of interest.

\section{References}

Aboujaoude, A. (2010). Problematic Internet use: An overview. World Psychiatry, 9(2), 85-90.

American Psychiatric Association. (2013). Diagnostic and statistical manual of mental disorders (5th ed.). Arlington: American Psychiatric Publishing.

Byrne, B. M. (2010). Structural equation modeling with AMOS: Basic concepts, applications, and programming, second edition (2nd ed.). New York: Routledge.

Csóka, S., Szabó, G., Sáfrány, E., Rochlitz, R., \& Bódizs, R. (2007). A measurement of adult attachment: The Hungarian version of the Relationship Scale Questionnaire (A Felnőttkori kötődés mérésére - a Kapcsolati Kérdöív magyar változata). Pszichológia, 27(4), 333-355 (in Hungarian).

Davis, R. A. (2001). A cognitive-behavioral model of pathological Internet use. Computers in Human Behavior, $17(2), 187-195$.

Demetrovics, Z., Szeredi, B., \& Nyikos, E. (2004). Introduction of the Problematic Internet Use (PIU) Questionnaire (A Problémás Internethasználat Kérdỏív bemutatása). Psychiatria Hungarica, 19(2), 141160 (in Hungarian).

Demetrovics, Z., Szeredi, B., \& Rózsa, S. (2008). The three-factor model of Internet addiction: The development of the Problematic Internet Use Questionnaire. Behavior Research Methods, 40(2), 563-574.

Durkee, T., Kaess, M., Carli, V., Parzer, P., Wasserman, C., Floderus, B., Apter, A., Balazs, J., Barzilay, S., Bobes, J., Brunner, R., Corcoran, P., Cosman, D., Cotter, P., Despalins, R., Graber, N., Guillemin, F., Haring, C., Kahn, J. P., Mandelli, L., Marusic, D., Mészáros, G., Musa, G. J., Postuvan, V., Resch, F., Saiz, P. A., Sisask, M., Varnik, A., Sarchiapone, M., Hoven, C. W., \& Wasserman, D. (2012). Prevalence of pathological Internet use among adolescents in Europe: Demographic and social factors. Addiction, 107(12), 2210-2222.

Engelberg, E., \& Sjöberg, L. (2004). Internet use, social skills, and adjustment. Cyberpsychology \& Behavior, $7(1), 41-47$.

Eroglu, M., Pamuk, M., \& Pamuk, K. (2013). Investigation of problematic Internet usage of university students with psychosocial levels at different levels. Procedia - Social and Behavioral Sciences, 103, 551-557.

Esen, B. K., Aktas, E., \& Tuncer, I. (2013). An analysis of university students' Internet use in relation to loneliness and social self-efficacy. Procedia - Social and Behavioral Sciences, 84(9), 1504-1508.

Fallahi, V. (2011). Effects of ICT on the youth: A study about the relationship between Internet usage and social isolation among Iranian students. Procedia - Social and Behavioral Sciences, 15, 394-398.

Gunuc, S., \& Dogan, A. (2013). The relationship between Turkish adolescents' Internet addiction, their perceived social support and family activities. Computers in Human Behavior, 29(6), 2197-2207.

Jelenchick, L. A., Eickhoff, J. C., \& Moreno, M. A. (2013). "Facebook depression?" social networking site use and depression in older adolescents. Journal of Adolescent Health, 52(1), 128-130.

Kitta, G. (2012). Use of the media among Hungarian youth (Médiahasználat a Magyar ifjúság körében). In L. Székely (Ed.), Magyar Ifjúság 2012 - tanulmánykötet (pp. 250-283). Budapest: Magyar Közlöny Lap- és Könyvkiadó (in Hungarian).

Ko, C. H., Yen, J. Y., Liu, S. C., Huang, C. F., \& Yen, C. F. (2009). The associations between aggressive behaviors and Internet addiction and online activities in adolescents. Journal of Adolescent Health, 44(6), 598-605.

Kowalski, R. M., Giumetti, G. W., Schroeder, A. N., \& Lattenner, M. R. (2014). Bullying in the digital age: A critical review and meta-analysis of cyberbullying research among youth. Psychological Bulletin, 140(4), 1073-1137.

Kraut, R., Lundmark, V., Patterson, M., Kiesler, S., Mukopadhyay, T., \& Scherlis, W. (1998). Internet paradox: A social technology that reduces social involvement and psychological well-being? American Psychologist, 53(9), 1017-1031.

Leary, M. R., Kelly, K. M., Cottrell, C. A., \& Schreindorfer, L. S. (2013). Construct validity of the need to belong scale: Mapping the nomological network. Journal of Personality Assessment, 95(6), 610-624.

Leung, L. (2004). Net-generation attributes and seductive properties of the Internet as predictors of online activities and Internet addiction. Cyberpsychology \& Behavior, 7(3), 333-348.

Leung, L. (2011). Loneliness, social support, and preference for online social interaction: The mediating effects of identity experimentation online among children and adolescents. Chinese Journal of Communication, 4(4), 381-399. 
Li, C., Dang, J., Zhang, X., Zhang, Q., \& Guo, J. (2014). Internet addiction among Chinese adolescents: The effect of parental behavior and self-control. Computers in Human Behavior, 41, 1-7.

McIntyre, E., Wiener, K. K. K., \& Saliba, A. J. (2015). Compulsive Internet use and relations between social connectedness and introversion. Computers in Human Behavior, 48, 569-574.

Murphy, K. R., \& Davidshofer, C. D. (1988). Psychological testing: Principles and applications. Englewood Cliffs: Prentice-Hall.

Naeemi, S., Tamam, E., Hassan, S. H., \& Bolong, J. (2014). Facebook usage and its association with psychological well-being among Malaysian adolescents. Procedia - Social and Behavioral Sciences, 155, $141-160$.

Piko, B. (2000). Perceived social support from parents and peers: Which is the stronger predictor of adolescent substance use? Substance Use and Misuse, 35(4), 617-630.

Rai, R. (2011). Shyness and sociability re-examined: Psychometrics, interactions, and correlates. Dissertation. Hamilton (ON): McMaster University https:/macsphere.mcmaster.ca/bitstream/11375/10693/1/fulltext.pdf Accessed 22 Aug 2016.

Russel, D., Peplau, L. A., \& Cutrona, C. E. (1980). The revised UCLA Loneliness Scale: Concurrent and discriminant validity evidence. Journal of Personality and Social Psychology, 39(3), 472-480.

Ságvári, B. (2012). Hungary. In L. Haddon \& S. Livingstone (Eds.), EU kids online national perspectives (pp. 29-30). London: The London School of Economics and Political Science.

Selfhout, M. H. W., Branje, S. J. T., Delsing, M., ter Bogt, T. F. M., \& Meeus, W. H. J. (2009). Different types of Internet use, depression, and social anxiety: The role of perceived friendship quality. Journal of Adolescence, 32(4), 819-833.

Shapira, N. A., Lessing, M. C., Goldsmith, T. D., Szabo, S. T., Lazoritz, M., Gold, M. S., \& Stein, D. J. (2003). Problematic Internet use: Proposed classification and diagnostic criteria. Depression and Anxiety, 17(4), 207-216.

Spada, M. M. (2014). An overview of problematic Internet use. Addictive Behaviors, 39(1), 3-6.

Turner, R. J., \& Marino, F. (1994). Social support and social structure: A descriptive epidemiology. Journal of Health and Social Behavior, 35, 193-212.

Vandelanotte, C., Sugiyama, T., Gardiner, P., \& Owen, N. (2009). Associations of leisure-time Internet and computer use with overweight and obesity, physical activity and sedentary behaviors: Cross-sectional study. Journal of Medical Internet Research, 11(3), e28 accessed Aug. 22, 2016.

Wasserstein, R. L., \& Lazar, N. A. (2016). The ASA's statement on p-values: Context, process, and purpose. The American Statistician, 70(2), 129-133.

Yen, C. F., Ko, C. H., Yen, J. Y., Chang, Y. P., \& Cheng, C. P. (2009). Multi-dimensional discriminative factors for Internet addiction among adolescents regarding gender and age. Psychiatry and Clinical Neurosciences, 63(3), 357-364.

Young, K. S. (1998). Internet addiction: The emergence of a new clinical disorder. Cyberpsychology \& Behavior, 1(3), 237-244. https://doi.org/10.1089/cpb.1998.1.237.

Young, K. S. (2004). Internet addiction: A new clinical phenomenon and its consequences. American Behavioral Scientist, 48(4), 402-415. https://doi.org/10.1177/0002764204270278.

Žumárová, M. (2015). Computers and children's leisure time. Procedia-Social and Behavioral Sciences, 176 , $779-786$. 